\title{
Ward Round-A rare tumor of the kidney resulting in hypertension, renal failure and a cerebrovascular accident in a young female
}

\section{E Broadis ${ }^{1}$, C Ntoto' 1 , S Kamiza²,E Borgstein'.}

1.Department of Surgery, College of Medicine, University of Malawi, Chichiri, Blantyre 3

2.Department of Pathology, College of Medicine University of Malawi, Chichiri, Blantyre 3

\section{Abstract}

A 17-year-old girl was admitted to our hospital with severe refractory hypertension evolving over approximately 4 years. Despite not having the resources to identify plasma-renin levels and using standard imaging techniques, a juxtaglomerular cell tumor was suspected and was histologically confirmed after surgical excision. This is a potentially lethal condition if left untreated and surgical excision is curative. The benign nature of the tumor is emphasized and its chemical, radiological and microscopic appearance discussed according to the literature.

To the best of our knowledge, this is the first reported case of a patient surviving a cerebrovascular accident associated with a juxtaglomerular cell tumor.

\section{Case Report}

A 17-year-old female was referred to our hospital with a fouryear history of hypertension. Initially this was associated with headaches but six months prior to referral she had suffered a cerebrovascular accident leading to a right hemiplegia.

Her blood pressure was poorly controlled, despite being on Furosemide 40mg once daily, Losartan 50mg once daily, Methyldopa 500mg three times daily and Captopril $12.5 \mathrm{mg}$ three times daily. She had no known drug allergies and there was nothing else specific in her medical or family history.

On examination her heart rate was 80 beats per minute and her blood pressure was 220/160. Her heart sounds were normal and her chest was clear. Her abdomen was soft and non-tender with no organomegaly or palpable masses.

Initial investigations included full blood count, urea and electrolytes, twice daily blood pressure monitoring and an ultrasound scan of her abdomen.

The results showed she was in renal failure with a urea of $74 \mathrm{mg} / \mathrm{dL}$ and creatinine of $5.1 \mathrm{mg} / \mathrm{dL}$. Her sodium was $140 \mathrm{mEq} / \mathrm{L}$, potassium $5.31 \mathrm{mEq} / \mathrm{L}$, chloride $102 \mathrm{mEq} / \mathrm{L}$, calcium $2.3 \mathrm{mmol} / \mathrm{L}$, phosphate $3.8 \mathrm{mg} / \mathrm{dL}$. Haemoglobin was $9.4 \mathrm{~g} / \mathrm{dL}$, white cell count $4.5 \times 103 / \mathrm{microL}$ and platelets $218 \times 103 /$ microL.

An ultrasound scan revealed a lesion in the left lower pole of her kidney. An MRI was performed which demonstrated a 3 $\mathrm{x} 3 \mathrm{~cm}$ tumor of the left kidney. (See Figures 1).

She was taken to theatre where a left lower pole nephrectomy was performed. Post operatively she was taken to the intensive care unit where she required peritoneal dialysis for three days.

By two weeks post operation she was ready for discharge. Her medications were weaned and her blood pressure stabilised at around 120/70 $\mathrm{mmHg}$. The furosemide, losartan and captopril were all discontinued and she was discharged home on folate $5 \mathrm{mg}$ od, iron sulphate 1 tablet bd and methyldopa $250 \mathrm{mg}$ bd.

The gross specimen consisted of a $3 \times 2 \mathrm{~cm}$ well circumscribed nodule.(Figure 2) caption see above. Histology revealed round to oval cells with moderate nuclear atypia and rare mitoses. See Figure 3. There were several intra-tumoral cysts containing pink secretions. In addition, prominent small arteries with hyaline arteriolosclerosis consistent with chronic hypertension were present. The clinical and morphological features confirmed the diagnosis of a juxtaglomerular cell tumor.

At 3 months follow up she was well with a normal blood pressure. Her methlydopa was being weaned.

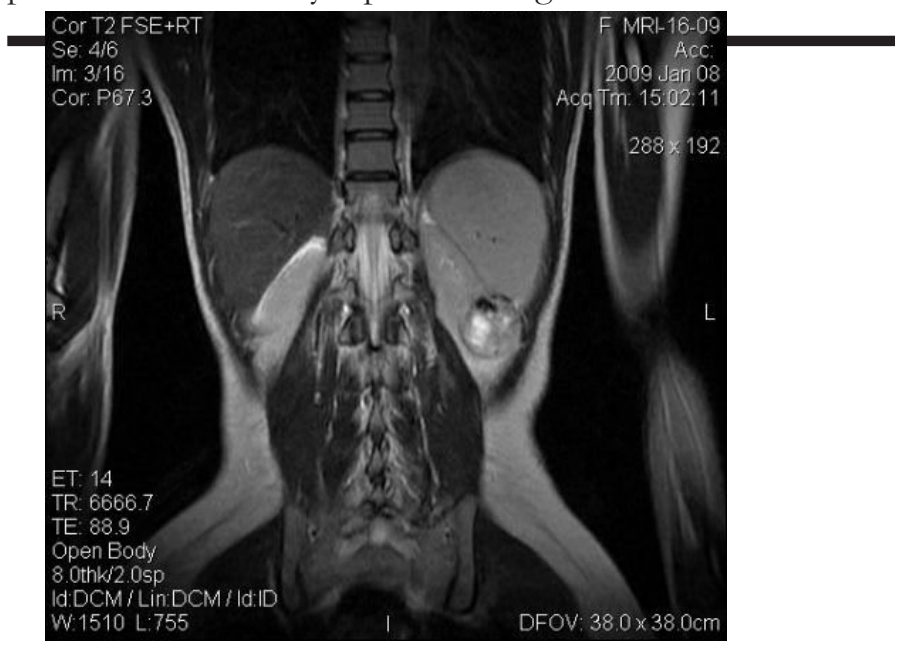

\section{Figure 1. Axial MRI view of tumor in left lower pole of kidney}

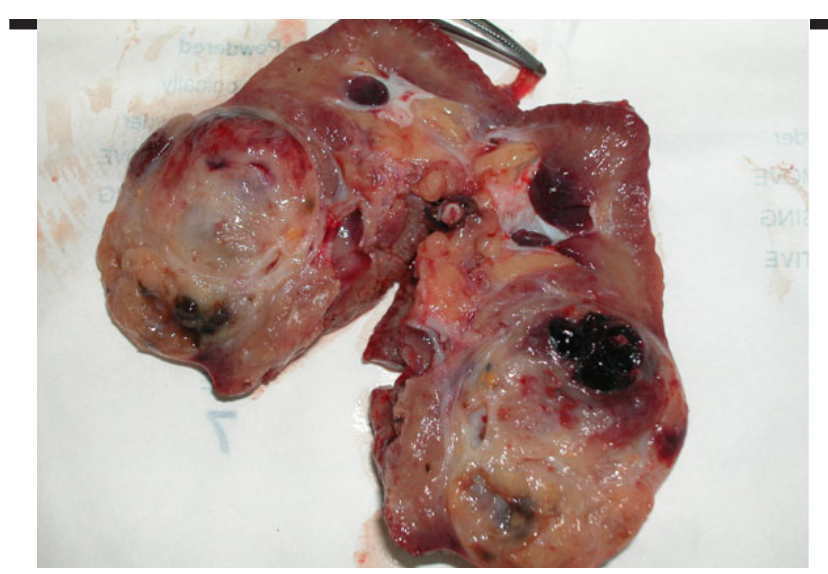

Figure 2. Operative specimen showing well demarcated tumour in the lower pole of the kidney

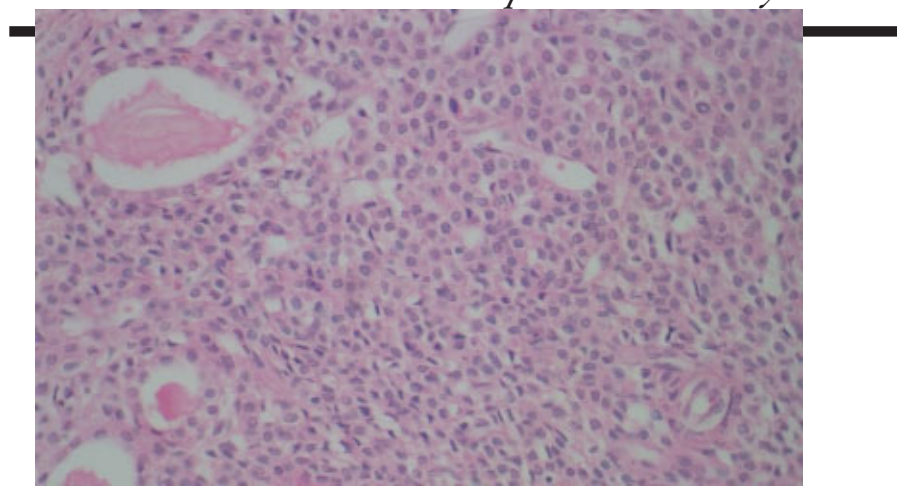

Figure 3. Histology showing round to oval cells with 


\section{moderate nuclear atypia and rare mitoses (H\&E, x200)}

\section{Discussion}

Juxtaglomerular cell tumors are rare, with less than one hundred cases reported in the literature. They are more commonly described in patients in their second and third decades of life and have a male to female ratio of around 1:2.1,2 All the cases described have been solitary lesions and it is generally thought of as a benign tumour as there has been only one reported case of malignancy. ${ }^{3}$ In the last few years cytogenetics have identified deletions on chromosomes $\mathrm{X}, 9$ and 11 in four cases ${ }^{4,5}$ and there is a suggestion that juxtaglomerular cell tumors should actually be thought of as having uncertain malignant potential.

The juxtaglomerular cells of the kidney are found in the afferent arterioles of the glomeruli and are the main source of active renin in the circulation. Renin initiates a series of enzymatic processes leading to the production of angiotensin II, a vasoactive molecule that plays a major role in blood pressure haemostasis. ${ }^{5}$

In the investigation of young adults with poorly controlled hypertension, juxtaglomerular cell tumor should be strongly considered in the differential diagnosis. ${ }^{6}$ Juxtaglomerular tumors are usually associated with secondary hyperaldosteronism and hypokalaemia, and were initially described in poorly controlled hypertensive patients as part of a clinicopathological syndrome. ${ }^{7}$ As well as urea and electrolyte measurements, many centres would advocate renal vein sampling and plasma renin and aldosterone measurements to lateralise renin activity and diagnose secondary hyperaldosteronism. Within our hospital there are limited laboratory tests available so these were not investigative options. Renin activity can also vary over time in the same patient, and it has been reported that lateralisation of renin activity fails in over half of cases. ${ }^{8}$ We suspect our patient did not have hypokalaemia due to the fact she was in renal failure.

In our patient the lesion was demonstrated on ultrasonography and further delineated on MRI scanning. Tanabe et $\mathrm{al}^{9}$ demonstrated that dynamic CT is useful in differentiating juxtaglomerular cell tumor from renal carcinoma due to the differences in uptake and washout of contrast, with renal cell carcinoma staining intensely during the early stages and having significant washout of contrast during the late phase compared to juxtaglomerular cell tumors which had no staining in the early phase but moderate staining during the late stage. The same group also described the case of a very small juxtaglomerular cell tumor $(8 \times 8 \mathrm{~mm})$, which was not seen on CT scanning but visualised as a high signal mass on T2-weighted Magnetic Resonance Imaging. ${ }^{10}$

Immunohistochemistry will distinguish juxtaglomerular cell tumors from other renal tumours. ${ }^{2,11}$ Juxtaglomerular cell tumors stain positive for CD34, which is negative in haemangiopericytoma. Renal cell carcinomas stain positive for cytokeratin, and angiomyolipomas stain positive for HMB-45, both of these are negative in juxtaglomerular cell tumors. ${ }^{12}$

To the best of our knowledge we know of only one other reported case of a patient who suffered a cerebrovascular accident as a result of hypertension secondary to juxtaglomerular cell tumor. ${ }^{13}$ In this patient the tumor was diagnosed at post mortem after the patient died from a massive cerebrovascular haemorrhage secondary to hypertension.

Our patient was a young girl who suffered unexplained hypertension for four years prior to renal investigation.
During this time she suffered a cerebrovascular accident and renal failure. With a renal ultrasound scan we were able to demonstrate a lesion in her left kidney, which together with the difficulty in medically managing her hypertension, pointed to a likely diagnosis of a juxtaglomerular cell tumor. Excision of the tumor resulted in normalisation of her blood pressure.

We performed an open nephrectomy as presently the equipment for laparoscopic surgery is not available in our institution, however there have been reports of successful laparoscopic partial nephrectomy. ${ }^{14,15}$

Due to the benign nature of juxtaglomerular cell tumors, and because they are usually small and peripherally located, there has been a move towards nephron sparing surgery ${ }^{15,16}$ instead of complete nephrectomy.

As more cases are reported in the literature and more is learnt about the condition a recent publication has recommended a new classification system into typical, atypical and nonfunctioning juxtaglomerular cell tumors depending on blood pressure and serum potassium. ${ }^{15}$

\section{References}

1. Min KO, Kwon HJ, Ahn SJ, Chang SA, Chang YS, Bang BK et al. Juxtaglomerular Cell Tumour of the Kidney: A Case Report. J Korean Med Sci 2001; 16: 233-6

2. Martin SA, Mynderse LA, Lager DJ, Cheville JC. Juxtaglomerular Cell Tumor. Am J Clin Pathol 2001; 116: 854-863

3. Duan X, Bruneval P, Hammadah R, Fresco R, Eble J, Clark J et al. Metastatic Juxtaglomerular Cell Tumor in a 52-Year-Old-Man. Am J Surg Path 2004; 28: 1098-1102

4. Shao L, Manalang M, Cooley L. Juxtaglomerular cell tumor in an 8-year-old girl. Pediatric Blood and Cancer 2008; 50: 406-9

5. Capovilla M, Couturier J, Molinie V, Bruneval P, Vieillefond A. Juxtaglomerular cell tumours: report of two cases with genomic analysis. Annales de Pathologie 2008; 28: 474-6

6. Pan L, Gross KW. Transcriptional Regulation of Renin. Hypertension 2005; 45: 3

7. Haab F, Duclos JM, Guyenne T, Plouin PF, Corvol P. Renin Secreting Tumors: Diagnosis, Conservative Surgical Approach and Long-Term Results. J Urol 1995; 153: 1781-4

8. Hanna W, Tepperman B, Logan AG, Robinette MA, Colapinto R, Phillips MJ. Juxtaglomerular Cell Tumor (Reninoma) with Paroxysmal Hypertension. CMA J 1979; 120: 957-9

9. Chambo JL, Junior RF, Lucon AM. Juxtaglomerular Cell Tumor as a rare cause of Hypertension in Adults. Int Braz J Urol 2004; 30 : $119-120$

10. Tanabe A, Naruse M, Ogawa Tetal. Dynamic Computer Tomography is useful in the Differential Diagnosis of Juxtaglomerular Cell Tumor and Renal Cell Carcinoma. Hypertens Res 2001; 24: 331-336

11. Tanabe A, Naruse K, Kono A, Hase M, Hashimoto Y, Nakazawa H et al. A very small juxtaglomerular cell tumour preoperatively identified by magnetic resonance imaging. Internal Medicine 1996; 35: 295-300

12. Markey RB, MacLennon GT. Juxtaglomerular Cell Tumor of the Kidney. J Urol 2006; 175: 730

13. Gherardi GJ, Arya S, Hickler RB. Juxtaglomerular body tumor: a rare occult but curable cause of lethal hypertension. Hum Pathol 1974; 5: $236-240$

14. Sugimoto M, Inui M, Yoshiyuki K. A case of juxtaglomerular cell tumor (reninoma) of the kidney treated with laparoscopic partial nephrectomy. Int J Urol 2009; 16:977

15. Dexin D, Hanzhong L, Weigang Y, Weifeng X. Juxtaglomerular cell tumor of the kidney - a new classification scheme. Urol Onc 2010; 28: $34-38$

16. Mete UK, Niranjan J, Kusum J, Rajesh LS, Goswami AK, Sharma SK. Reninoma treated with nephron-sparing surgery. Urology 2003; 61: 1259iii-iv 